Intracranial Tumour:

To explain how relief can be obtained by means of hypertorsic solutions in cases of intracranial tumour it is necessary to give a brief account of the way in which a rise of intracranial pressure is brought about in this condition. We may recognize three factors which contribute to this result-the direct pressure of the tumour, the effect of the tumour upon the intracranial circulation, and the combination of both of these factors to produce internal hydrocephalus. It is easy to understand that the growth of a tumour within the brain raises the intracranial pressure in its immediate neighbourhood. In addition, by pressure upon surrounding veins, it raises the venous pressure locally, and in many cases throughout the whole cranial cavity. The local venous congestion leads to oedema of areas of brain surrounding the tumour, and so intensifies the local rise of pressure. The main causes of internal hydrocephalus in cases of intracranial tumour are obstruction to the free passage of fluid from the ventricles by the tumour, and the general rise of intracranial venous pressure, which leads to both increased formation and impaired absorption of cerebro-spinal fluid. Thus an intracranial tumour sets up a series of vicious circles whereby the intracranial pressure, once raised, tends to rise more and more.

The value of hypertonic solutions in cases of cerebral tumour lies in the fact that they break these vicious circles and permit a readjustment of the volumes of the intracranial contents which may last for a considerable time. This they do mainly by reducing the formation and increasing the absorption of cerebro-spinal fluid, and so temporarily relieving the hydrocephalus. The following are the chief indications for employing them.

1. As an Aid to Diagnosis.-Not uncommonly a patient with an intracranial tumour is in a semi-comatose condition when first seen, and is quite unable to co-operate in the examination of sensibility or the visual fields. In such cases two or three rectal injections of magnesium sulphate solution may be sufficient to restore the patient to consciousness and render a full examination possible.

2. In Emergencies.-If a patient with an intracranial tumour suddenly becomes comatose, as may occasionally happen after ventriculography or in other circumstances, ail intravenous injection of hypertonic saline may reduce the intracranial pressure sufficiently long to permit operation to be performed.

3. As Palliative Treatment.-Tin inoperable cases or while a patient is awaiting operation it is often possible to relieve headaches and vomiting by giving magnesium sulphate either by the mouth or by the rectum.

Cerebral Haemorrhage.

Both Leonard Hill and Cushing showed a good many years ago that the injection of fluids under pressure into the subarachnoid space led to a rise of blood pressure. This response of the vasomotor centre to a rapid rise of intracranial pressure is responsible for yet another vicious circle in intracranial pathology. The majority of cerebral haemorrhages occur in patients whose blood pressure is already high, but the haemorrhage, by raising the intracranial pressure, tends to cause the blood pressure to rise still further, and this in turn favours the continuance of the bleeding, or may even result in further haemorrhages elsewhere. Thus a rising blood pressure in a patient with a cerebral haemorrhage may be taken to indicate that the bleeding is still continuing. On the strength of these facts it has been urged that venesection is contraindicated in cerebral haemorrhage, because the medulla is already threatened with anaemia, and to withdraw blood from circulation is to add to its difficulties. Those who hold this view advocate lumbar puncture as the correct treatment, since by this means the intracranial pressure can be directly reduced without restricting the blood supply to the medulla. When the intracranial pressure is lowered, it is said, the blood pressure will fall, and the bleeding is then likely to stop.

These arguments against venesection and in favour of lumbar puncture do not take account of all the circumstances. I have never seen benefit result from lumbar puncture in a patient suffering from cerebral haemorrhage, and $I$ believe it to be definitely contraindicated in such cases. There are two serious risks attaching to it. The fall of pressure in the spinal theca may lead either to the rupture of the haemorrhage into one of the ventricles or to the downward displacement of the contents of the posterior fossa into the foramen magnum, in either case with rapidly fatal results. Venesection, on the other hand, could hardly have enjoyed so enduring a reputation in the past as a mode of treatment of cerebral haemorrhage if its results were uniformly harmful. If it merely reduced the blood pressure without at the same time lowering the intracranial pressure it would clearly be a dangerous procedure. Actually, however, since the intracranial pressure is ultimately dependent on the blood pressure, a fall in the blood pressure leads to a reduction of the intracranial pressure. Moreover, a diminution in the volume of the circulating blood also leads to a fall of intracranial pressure. Hence the theoretical risk of increasing the medullary anaemia is compensated by the relief afforded by a lowered intracranial pressure. Further, we must place to the credit side of the transaction the tendency of the lowering of the blood pressure to check the haemorrhage, its relief of the strain upon the heart, and its influence in increasing the coagulability of the blood. Venesection is therefore a rational form of treatment for cerebral haemorrhage.

Hypertonic solutions have only a limited value in this condition. Intravenous injections are contraindicated as tending to raise the blood pressure, and it is doubtful if the rectal mode of administration can influence a haemorrhage which is still in progress. The rectal injections, however, may be of value as a means of reducing the intracranial pressure in patients in whom there is reason to believe that the haemorrhage has stopped but who show no signs of recovering consciousness. Free purgation reduces the intracranial pressure in exactly the same way as hypertonic solutions administered by the alimentary canal, and possesses the same physiological justification.

\section{Other Conditions.}

There are other conditions associated with increased intracranial pressure in the treatment of which hypertonic solutions are useful. In the post-operative treatment of cerebral abscess they may be used to reduce oedema of the brain around the abscess cavity, and so diminish a tendency to herniation and promote drainage. They are also of value for the relief of headache in epidemic encephalitis and meningitis. Other applications will suggest themselves, but enough has been said to show that Weed's discovery has rendered available therapeutio methods of the greatest value in diseases of the nervous system.

\section{EXPERIMENTS IN MALNUTRITION.* \\ BY}

\section{H. MOTTRAM, M.A.CAMB.,}

PROFESSOR OF PHYSIOLOGY IN THE UNIVERSITY OF LONDON, AND HEAD OF THE PHYSTOLOGY LABORATORY, KING'S COLLEGE FOR WOMEN (HOUSEHOLD AND SOCIAL SCIENCE DEPARTMENT).

The lines along which a diet may be inadequate so as to entail malnutrition are many. It may be insufficient in quantity or in quality. It may yield too little building material (protein mainly), too little fuel material (fats, carbohydrate, and surplus protein), or too little in the way of catalysts (mineral matter-for example, iron, iodine, calcium-and vitamins). The quality of the proteins may be poor-cereal proteins not having the biological value of meat or milk proteins. The diet may be inadequate because it has too little (or even perhaps too much) roughage, because the proportions between the different constituents are wrong, or because the way in which the food is presented is wrong.

It is clear from this that it is extremely difficult to work out experimentally the different possibilities of

* A lecture delivered to the St. Pancras Division of the British Medical 
wrongness of diet. Only a few broad lines are to be illustrated here by experiments on animals. It is not maintained that all, or any, of them are directly applicable to the feeding of human beings. But they may point the way for observations to be made on human beings, and that is why they are now being offered.

Bread is an inadequate diet for a nursing mother rat

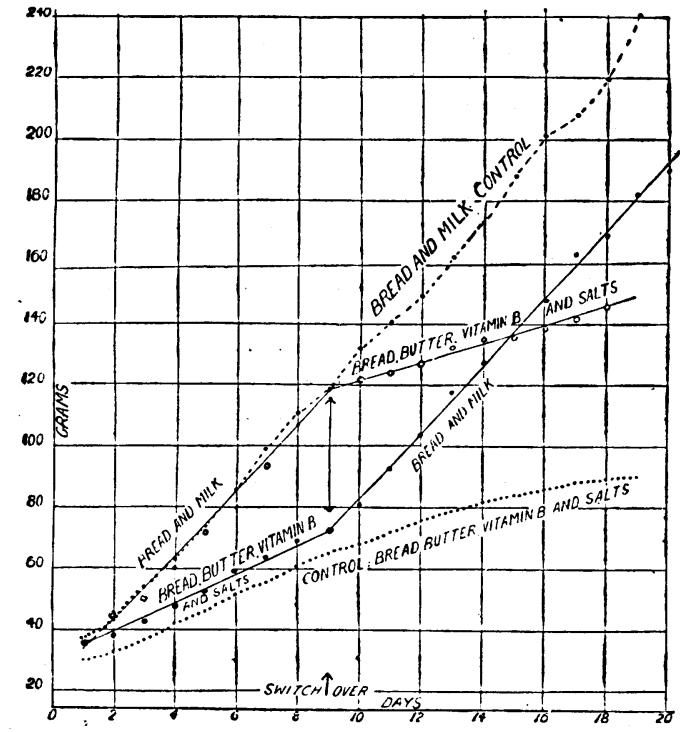

Fig. 1.-The growth rate of two sets of suckling rats when their mothers are on a poor diet (bread) and a rood (bread and milk) respectively. At the ninth day, when the diets were changed in both cases-in one from good to poor and in the other from poor to good-a change in the rate of growth was almost immediate.

and her offspring during the nursing period. Fig. 1, for the data for which $I$ am indebted to Dr. Gladys Hartwell, brings out the point very clearly. Suckling rats whose mothers are receiving bread grow at but half the rate of those whose mothers are on bread and milk. Moreover, there is an immediate response to a change in diet. Within twenty-four hours a change from a good to a bad diet, or from a bad to a good, shows up on the offspring's weight record.

Now the inadequacy of bread is not due mainly to its lack of vitamins $\mathbf{A}$ and $\mathbf{D}$, to its poverty in vitamin $\mathbf{B}$, nor to its lack of mineral matter. Young rats put on a diet of bread, mineral matter, butter, and marmite grow very slowly-approximately 1.42 grams per day. Such a diet is adequate as regards vitamins $\mathbf{A}, \mathbf{B}$, and $\mathbf{D}$, and as regards salts. Others on a mixed diet grow at the rate of 4.7 grams per day, or about three and a quarter times as fast. (Figs. 2 and 3.) It may be that either the quantity or the quality

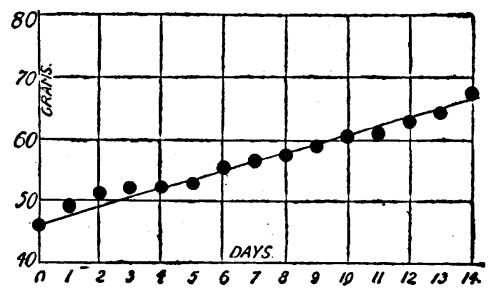

Fig. 2.-Slow growth on a diet of bread, salts, and materials to supply vitamins $A, B$, and $D$ only ( $C$ is unnecessary for rats).

of the proteins is at fault. These possibilities can be tested (i) by adding gluten, the mixed proteins of white flour, and (ii) by adding an acknowledged first-class protein, such as casein, to a bread, salt, and vitamin diet, and observing the growth of the young. If the addition of gluten improves the growth (and it does-see Fig. 4), then bread is deficient in its protein content. If the addition of casein still further improves the growth rate (which is the casesee Fig. 5), then bread is deficient not only in the quantity but in the quality of its protein.

It is tempting to superimpose these four curves, as in
Fig. 6, so as to bring out more clearly the facts stated above, but scientifically it is not quite fair, because although the three upper growth rates were obtained from most carefully controlled material used simultaneously, the growth rate on bread alone was obtained the year before at a somewhat later date in the year and on stock slightly

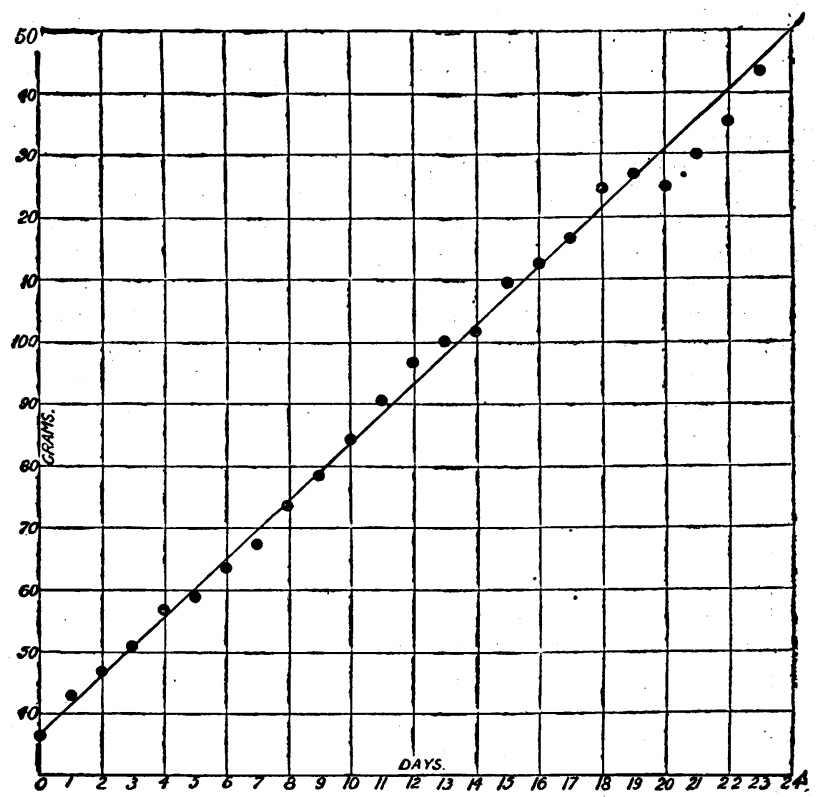

FIG. 3.-Maximal rate of growth on a mixed diet.

heavier. (The dotted line in Fig. 6 shows the actually observed growth rate.)

The inadequacy of bread is, apart from possible defects in vitamin and salt content, due both to the small quantity (8 to 10 per cent.) and poor quality of its protein. If this holds true for man-as is likely-there is nothing to be gained by using other wheat-flour foods such as macaroni, with its slightly higher proportion of gluten. What is needed is the addition of proteins which will "supplement" those of bread. Cereal proteins have but small amounts of lysine present in their molecules, while animal

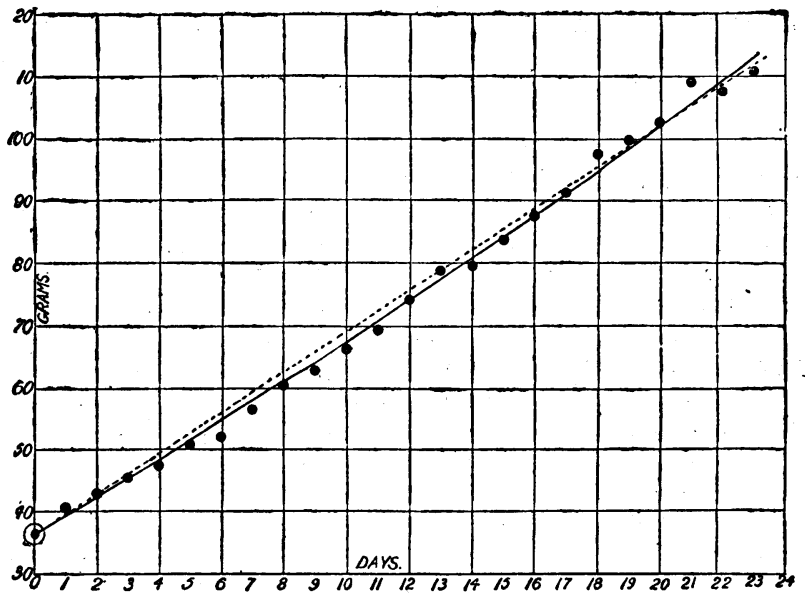

Fig. 4.-Growth rate on a diet of bread, salts, and vitamin containing materials to which extra protein from flour was added. (Compare Fig. 2.)

proteins, even gelatin, have relatively much larger amounts. Consequently, the addition of gelatin, which by itself is a useless protein, ${ }^{12}$ to a wheat protein ${ }^{3}$ or to bread ${ }^{4}$ results in a mixture which has high food value. White bread supplemented with gelatin enables young rats to grow better than upon white bread plus gluten."

The inadequacy of bread is shown not only in the growth rate of young animals, but in the deficiency of their coats. They become bald for a time, though they ultimately grow hair again. Their final coats on a bread diet are never 
so thick as when the animals receive a control mixed diet. The fault lies with the low quantity of protein in the bread, for addition of extra gluten prevents the occurrence of baldness. So, too, do casein and gelatin, though addition of vitamin B does not. ${ }^{5}$ An allied result is the paling of the pigmented areas of the animals' coats. Rapid growth with poverty of diet leads to greying of the hair; which darkens again very soon if satisfactory protein, such as casein, is supplied. ${ }^{\circ}$

A further interesting and significant fact is that the inadequacy of bread shows more clearly with males than with females. Normally the male rat is larger than the female, but upon an inadequate diet, such as bread, his growth rate is smaller. This is partly due to the nature of the protein, for if an animal protein is added to the diet the male regains his normal superiority, while if only gluten be added he does better than on bread alone, but only equals the female in weight. (It is interesting to note that gelatin supplements the proteins in bread in this respect too-the combination of two proteins, both poor, results in a pabulum which, if not quite first rate, is better than bread plus gluten.)

The extra growth of the male is dependent on another

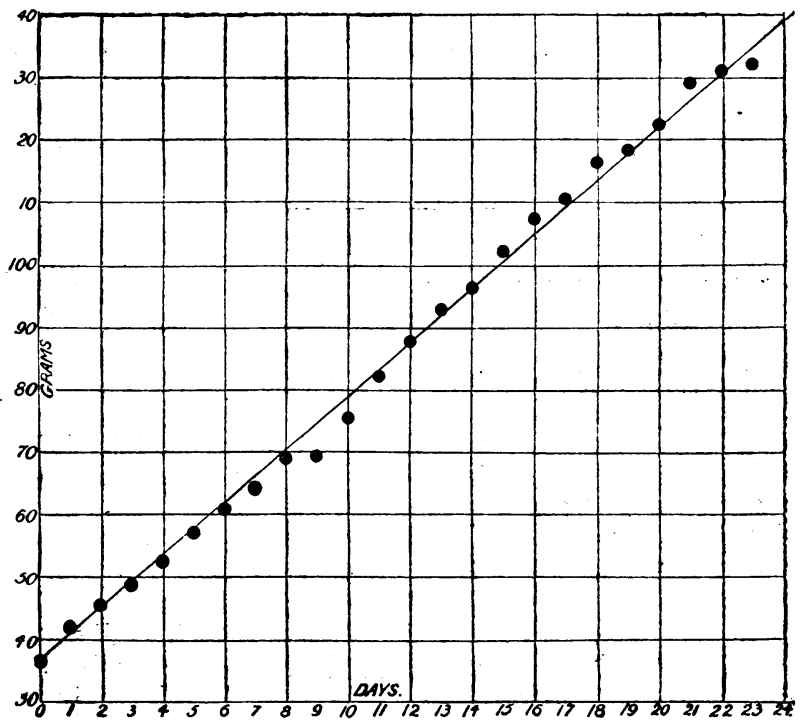

Fic. 5.-Growth rate on a diet of bread, salts, and vitamin con. taining materials to which casein from milk was addeú

factor as well-vitamin $B$. The addition of a preparation from yeast containing no protein (though amino-acids are present) enables the male to resume his normal comparative stature. $^{5}$ Perhaps it is the co-operation of these two factors (better protein and more vitamin B) which accounts for the slightly improved growth when brown bread is used instead of white in experiments on malnutrition.

This raises at once the problem of the relative merits of brown and white breads. The main trouble of entering such a discussion is that the protagonists on each side have an odium for the other almost theological-a sure sign of the insecurity of the foundations of their beliefs.*

There are some fundamental ad hoc experiments ${ }^{7}$ on the relative values of brown and white bread which have rarely received attention from either party of combatants. Rats of highly stable stock were placed on a dietary of ibread (white or brown), salt mixture, and water. The brown bread was baker's bread made from whole-meal from which a portion of the white flour had been removed-that is, it was "super" brown bread, and had more of the materials supplying vitamin $B$ and protein than straight whole-meal bread. The experiments showed that white and brown breads are equally good-or perhaps we had better say equally bad-for the growth of female rats, for gestation and lactation. Only in the growth of the males was the brown bread superior. How bad they both were can be seen from the fact that males and females starting at about 40 grams would, on a normal diet, be well over

* See an acrimonious correspondence in the Lancet, November 26th and December 10th, 1927 .
100 grams in weight at the end of four weeks, the females on brown or white bread weigh only about 55 , the males on white 55 and on brown 70 . Even the best grown animals on either bread grew at only half the rate of those on a mixed diet.

There is thus in these experiments little evidence except as to the badness of white and brown bread as the sole sonrce of proteins and calories. The marked superiority of brown over white bread, claimed by its adherents, "can be due only to its greater content of mineral matter-a point which the above experiments unfortunately do not settle. The results of the exclusive use of brown or white bread were so bad that it seemed not worth while to carry the experiments further.

The crying need at the present moment is for experiments comparable with those on the food value of milk carried out by Dr. Corry Mann ${ }^{8}$ under the auspices of the Ministry of Health and the Medical Research Council. It will be remembered that in these experiments the boys in one of the houses of a charitable institution, all fed from the same central kitchen, received in addition to the normal

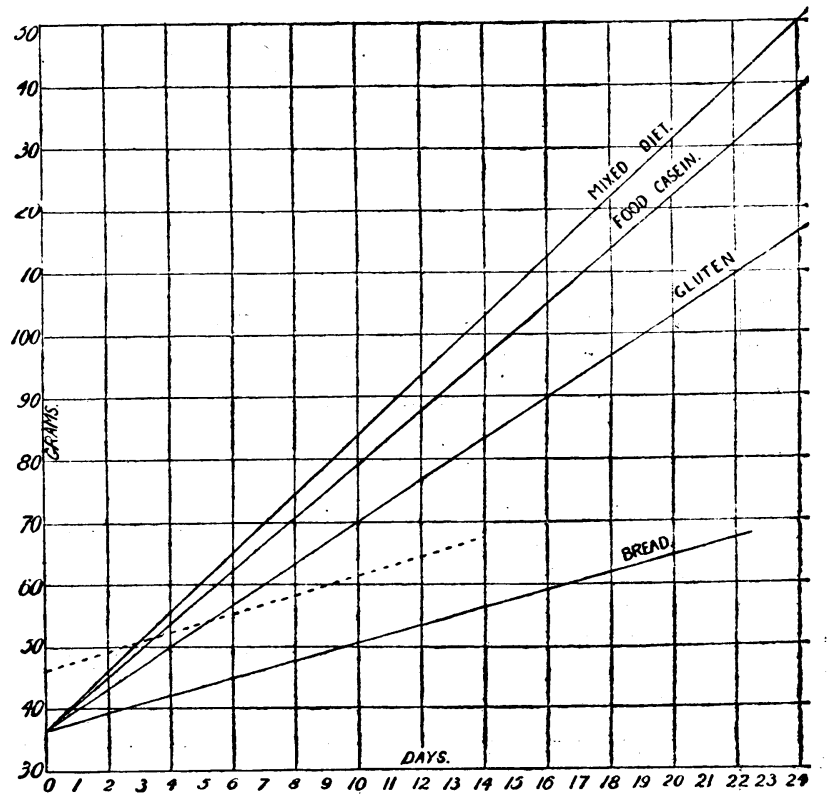

Fig. 6.-Superimposition of growth rates shown in Figs. 2 to 5 . FIG. 6.- Superimposition of growth rates and vitamin containing materials is as shown on-the dotted line.

diet one pint of milk per day. It would be easy, though somewhat costly, to carry out a similar experiment on the merits of brown bread in the feeding of growing boys. One house could have the white bread normally served substituted by brown bread, and the effects, if any, observed over a period of two or three years. Until such experiments have been carried out, and until they show a positive result, there seems no reason to act upon the advice of the enthusiasts for brown bread and compulsorily upset the dietetic habits of the nation.

A side issue of the experiments on malnutrition of the growing animal is, how long does it take for recovery? If the defective diet is given during the first half of the nursing period the answer is, not during the nursing period (see Fig. 1); if after weaning, recovery from its effects takes an unexpectedly long time. ${ }^{9}$ Thus thirteen days' malnutrition, due to a deficit of quality and quantity of protein, but of nothing else, produces such a retardation of growth that it is seven weeks before the animals approximate in weight to the controls, though they receive a diet which promotes an optimal growth rate. In this human beings apparently behave very differently from the experimental pied rat: the results of five weeks' malnutrition may be obliterated in as little as six-weeks. A possible reason for this difference is that a day is so much greater a percentage of a rat's life than of a human being's. Thirteen days is about one-tenth of a rat's growing period; five weeks, one two-hundredth of a child's.

It is not only in direct feeding of a young growing rat 
that the inadequacy of diet is made apparent. The same is true, as was stated above in the opening paragraphs, during lactation. If the nursing mother rat has an inadequate diet it results at once in a slowing of the growth of the offspring. ${ }^{10}$ A change in the diet from adequacy to inadequacy or vice versa results in a change in the rate of the growth of the young. (Fig. 1.) The problem at once arises: What is the best diet during the nursing period and after? As regards the brief period of nursing, bread and milk is the best yet investigated, and a mixed diet (kitchen scraps from the students' hostel) for the rest of the animal's existence. It is possible that a mixed diet would be equal to the bread and milk diet for the nursing period, but owing to technical difficulties

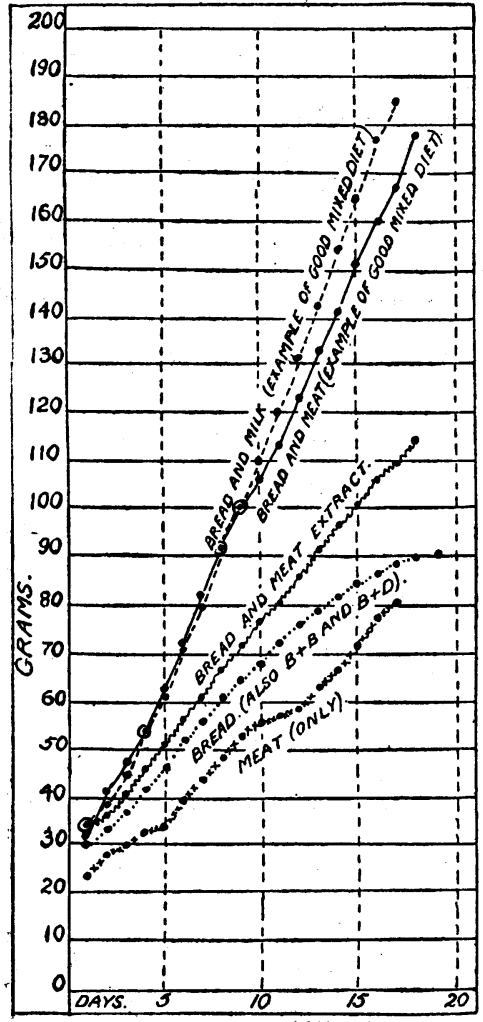

FIG. 7.-Growth rates of young when mothers are on different diets. that has not yet been investigated. Fig. 7 shows the growth rates. of suckling rats when their mothers are on different simple diets. ${ }^{11}$ It will be noticed that bread and meat is nearly equal in value to bread and milk, while bread alone, bread-andbutter, bread and dextrin are far behind. Meat alone gives a very poor growth, which may be due (1) to the impossibility of eating sufficient bulk of food, or (2) to the lack of balance between the excess of protein and the vitamin $B$ in the diet (vide infra).

An attempt to improve the value of the diet of bread alone by adding a commercial protein led to a curious result which cannot be without significance in problems of human nutrition. When a mixture of one part by weight, or even less, of protein to three parts of bread is given, the young grow well for

about ten days and then begin to develop symptoms of a striking character. ${ }^{12}$ There are violent tetanic spasms from time to time which leave the young animals oxhausted. Should the diet be not at once changed there is a rapid loss in weight and the young die, whereas tho mother is not markedly affected. She may lose weight, and if she does to any great extent the young are protected in part from disaster. Sometimes the fits are delayed till about the eighteenth day, when they are much more violent. The animal, in between the fits, walks on tiptoe, as though there were a permanent extensor spasm, and when the fits supervene dashes violently about the cage screaming, or rolls over in convulsions with the jaws locked in an open position. Death is the usual sequel. Fig. 8 shows the effect on growth rate when the symptoms come on eaily.

These results can be entirely avoided by giving large quantities of milk in the diet, and an extended investigation has fairly conclusively proved that it is the vitamin $\mathbf{B}$ content of the milk which obviates the trouble. Any preparation which contains vitamin $\mathbf{B}$ in considerable amount, such as marmite, juices of potato, tomato, or carrot, wheat germ extract, or soya bean extract, will prevont untoward happenings. ${ }^{13}$ It has been shown that, to bring up offspring successfully, when there is much protein in the diet the nursing mother needs three to four times as much vitamin $\mathbf{B}$ as is necessary for growth and reproduction. ${ }^{14}$ A tentative explanation, ${ }^{15}$ once vigorously controverted ${ }^{16}$ but now accepted, ${ }^{17}$ is that vitamin $B$ is essential as a catalyst for excessive protein metabolism.
That traces of such a condition should not make their appearance in the nursing of children is inconceivable, though up to the moment of this lecture we are unaware of any description of this. The old-fashioned but still common method of feeding the nursing mother on plenty of " strengthening food "-that is, a high protein dict-while cutting her off from vegetables and fruits; with the exception of the completely useless grape, is surely heading for trouble if nutritional work on animals has any bearing upon human nutrition. That they have such a bearing can hardly be denied, as work upon xerophthalmia (keratomalacia), beri-beri, scurvy, and rickets shows. It is true that results obtained upon animals under laboratory conditions of careful control have to be confirmed upon human beings under the much more difficult conditions of private practice, where the world is the laboratory and scientific controls are almost impossible. And sometimes the findings on human beings conflict with those of the laboratory, ${ }^{18}$ though none the less the laboratory results must not be neglected. They may lead to the discovery of hitherto unrecognized symptoms of disease, may help to expla in already known symptoms, and point the way to the prevention or cure of disease in human beings. It is in the hope that the results of the experiments upon nutrition briefly outlined above may be of value in clinical work that they are here presented.

Summary. 1. The inadequacy of bread as a diet is due mainly to the inadequacy of the quantity and quality of its protein.

2. Animal proteins, even gelatins, supplement the proteins of bread, and the mixture has a high biological value.

3. Males need more protein of high biological value and more vitamin $B$ than females.

4. Both brown and white breads are, by themselves, poor articles of diet. There is as yet no direct evidence that in a mixed diet brown bread is superior to white.

5. There is strong evidence from animal work that for successful nursing of young the vitamin $B$ content of the diet must be high.

REFERENCES.

1 Martin, C. J., and Robison, R. : Biochem. Journ., 1922, xvi, p. 407.

2 Robison, R. ' Jbid., 1922, xvi, p. 111, and many other authors.

3 Osborne, T. B., and Mendel, L. B.: Journ. Biol. Chem., 1912, x

Hartwell, G. A. : Brit. Journ. of Exper.
s Idem: Biochem. Journ., 1925, xix, p. 75.

6 Idem : Ibid., 1923, xvii, p. 577

Idem : Ibid., 1924, xviii, pp. 120 and 1323. Also Ref. 4 (Sup.).

Mann, H. C.' Corry : Medical Research Council, Special Report No. 105 Motram $\mathrm{V}$. Physiol., 1924, lix, p. lxi.

Biochem. Journ., 1921, xv, p. 140.

13 Idem : Ibid., 1922, xvi, p. 78.

15 Idem : lbid., 1922, xvi, pp. 78 and 825

16 Drummond, Crowdon, and Hill : Journ. Physiol., 1922, lvi, p. 413.

17 Reader, V., and Drummond, J. C. : Biochem. Journ., 1926, xx, p. 1256.

18 Stefánsson, V.: Journ. Amer. Med. A8soc., 1918. 